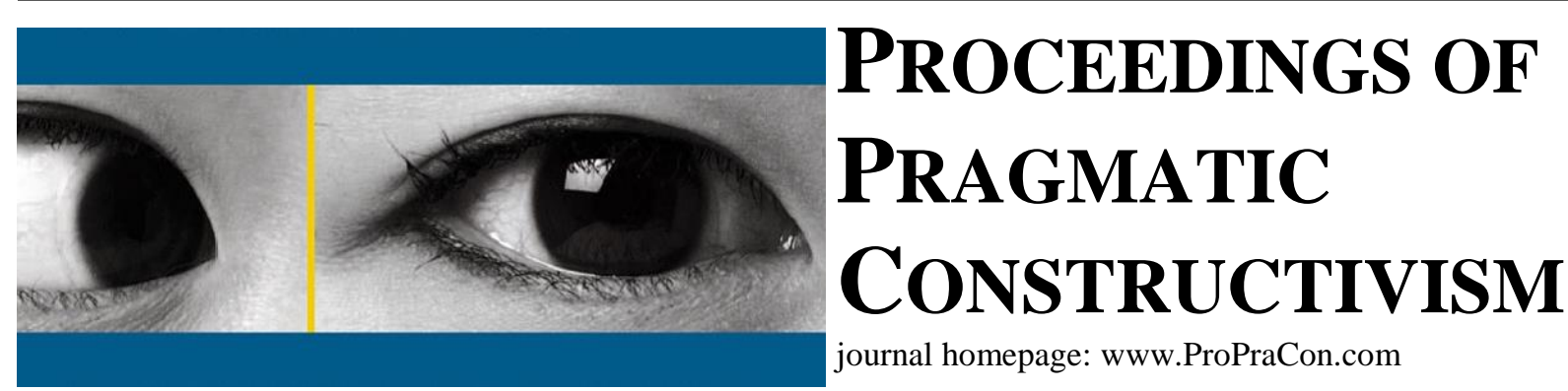

\title{
Beyond the Post-Truth Turn: From Habitus Based to Paranoiac Based Performance Management
}

\author{
Lennart Nørreklit \\ Professor Emeritus, Aalborg University, Denmark.
}

E-mail: lennartnorreklit@gmail.com

\author{
Lisa Jack \\ Department of Accounting \& Financial Management \\ Portsmouth Business School, University of Portsmouth, UK. \\ E-mail: lisa.jack@port.ac.uk \\ Hanne Nørreklit \\ Department of Management, \\ Arhus University, Denmark \\ E-mail: hannenorreklit@mgmt.au.dk
}

In recent decades most public-funded Western universities have been subjected to the governance principles of New Public Management (Craig, Amernic and Tourish 2014). The corporate university has replaced a profession-driven governance system that had developed over centuries in Western universities. It implies Universities are to be governed as a corporation with responsible management. The university is expected to be three different types of institution simultaneously: an academic community, a bureaucracy and a business corporation (Barcan 2013) The academic is expected to embody (be the victim and vessel for (Barcan 2013 p. 69) the physical, intellectual and emotional work involved in making these three cohere, become integrated.

The governance paradigm is dominated by the notion of 'excellence' and quantitative thinking. Based on Readings' (1996) prescient 'The University in Ruins’ Barcan (2013, p. 68) comments that “Content, he famously declared, is being supplanted by the notion of 'excellence'. He sees excellence as an 'integrating principle' rather than an ideology per se, for it 'has no content to call its own'. Rather, it is a 'unit of currency within a closed field' - a set of measures that assume that there is a 'single standard...in terms of which universities can be judged', irrespective of content.” In particular facilitated by the capacity of the information technology to collect and calculate (Big) data, governance models are progressively observed to capture 'excellence' around the use of all kind of performance measures such as journal rankings, league table placing, student survey scores, external, funding, on time delivery, etc. (Barcan 2013; O’Neil 2016).

The increased collection and calculation of data might provide a certain knowledge foundation for controlling the university managers and employees and make them more accountable to the society (Messner, 2009). However, there are also some dysfunctional effects of living with the quantified control. For instance, analysing the current academic ranking systems, Adler and Harzing (2009) suggest that current systems are dysfunctional and potentially cause more harm than good, a temporary moratorium on rankings may be appropriate until more valid and reliable ways to assess scholarly contributions can be developed. On line with this "Burrows (2012) finds that the metrics: “... increasingly function autonomously as a data assemblage able not just to mimic markets but, increasingly, to enact 
them." Also, the hybridity of the corporate university leads to dissonance, for 'when traditional and emergent institutional forms meet and overlay each other, there is an unavoidable collision of logics, purposes, values and demands, resulting in complex and dynamic modes of existence' (Barcan 2013, p. 87).

Also, the governance paradigm might give extensive space to: "the stresses and strains of being a member of the new economy: sometimes it seems as if all managers have found is a way to oppress themselves as well as workers... (Thrift 2005, p. 152). The competitive proving of merit, the generation of anxiety and fantasies of control, leads to fetishes of speed, reachability, multitasking and synergy, an environment that risks being unorchestrated, distracting and delusional (Barcan 2013). Craig, Amernic and Tourish (2014), state that the extreme measurement and audit culture of modern universities is a psychotic culture, as it is "showing signs of becoming 'delusional'; of having a defective 'contact with reality'; and of being paranoid schizoid” (p. 6). Further they argue that a paranoid schizoid form of university management is a defence mechanism. In an audit culture, the university is 'splitting' an 'object' (its reputation for research) into a good category (which is idealised) and a bad category (which is despised). This provides a defence mechanism for the university: it keeps the good and bad separated and controlled. It helps avoid anxiety situations by retreating into bureaucracy (Craig, Amernic and Tourish, p. 15).

For the individual researcher who must embody and absorb such audit and psychotic culture, the implication might be a constrain in their possibility to put forward arguments and express themselves academically: "How might we engage critically with the multiple moments in which individuals report being at breaking point, say 'my work is crap' or 'I'm going to be found out' - as well as those moments of gratuitous attack and cruelty, so often seen - for example in anonymised referee processes (yet rarely challenged) ...?” (Gill 2009: p. 229) Nevertheless, academic values still exist but contend with notions of expertise and the story of 'the managers who built the excellent university'. (Barcan 2013, p. 87). Thus although content of what we research and teach might not matter in the measurement of the excellent university and the version of 'success' and 'failure' they produce, it "still matters to politicians and to the public in other ways' because the university is seen as central to economic and ideological investments in the State" (Barcan 2013)

These findings give reason to be anxious about whether the extreme measurement facilitated by information technology jeopardize the professional academics. In view of that this paper is concerned about whether the language embedded in the information technology-based governance models' production and use of data facilitate a governance culture that put the academic agenda under pressure.

We address the question both theoretically and empirically. Theoretically, we are concerned about the nature of the lived-language game that constitute the social factory that must function pragmatically versus the digital language embedded in information technology and the implications of changing the language of control into the digital language for leadership and academic expression. More specifically, we draw on Wittgenstein's later work (1953) that conceives practice as a life form organised around language games that constitute the social factory and on pragmatic constructivism to outline what is required to create functioning practice (L. Norreklit 2017a, b). Emphasizing the cognitive complexity embedded in the live language games of capable practices, we use the term a habitus based language game. Subsequently, we identify the language scripting characteristics of IT systems. The language of IT encapsulates an analytical idea of meaning derived from logical positivism. This is further guided by a form of digital language close to that found in the philosophy of language of Wittgenstein's earlier work, Tractatus LogicoPhilosophicus (1921). Specifically, we discuss whether the digital language make the change into a psychotic or posttruth culture possible.

The empirical part sets of introducing the language game of the conventional university governance. Subsequently. it analyses the language driving the production and use of the IT-based measurement systems of universities and the evidence that individual managers in universities can develop leadership modes that are oppressive to the voice of the academics. The paper reveals that Excel Spreadsheet' epitomizes digital scripts. It illustrates how an extensive use of digital scripts as control tools create operational paths that crowd out professional academics. Also, the digital scripts pave the way for the construction of a post-truth state or psychotic.

In a post-truth environment, the managers in thrall to the digital language of control might use it for the establishment of paranoiac targets as a way to exert power and leadership. We reveal that in an organisational context with conflicting values prevailing narratives of both managers and the managed are paranoiac in ways that was less evident in the past, and this can be linked to these widespread changes in the language of control into the digital language embedded in information technology thus contributing to a post truth culture. Even so there is a palpable change in University work place narratives, the governance problems of favoritism and prejudice have not been solved by the extended use of control systems dominated by the digital founded scripts.

Universities are important to investigate because of they play a unique role in that they are the institutions that provide the foundation for a scientific basis where a scientific basis, the secularization, separates from issues of belief, habit and tradition. However, we think that our study is relevant most other public institutions in western societies are subject to new public management, because they are faced with similar measurement and audit culture. 